$\underline{\mathbf{P}-204}$

\title{
Ethnomedical Survey of Plants Used by Two Tribe of Orang Asli in Peninsular Malaysia
}

\author{
Muhamad Abdullah ${ }^{1}$, Regina Mariah Jong ${ }^{1}$, Nor Hafizah, ${ }^{2}$, Ahmad Ikhmal Razei, A. ${ }^{2}$ and \\ Shamsul, $\mathrm{K}^{2, *}$ \\ ${ }^{I}$ Silviculture and Forest Biodiversity Conservation Division Forestry Department Peninsular Malaysia, Jalan Sultan \\ Salahuddin, 50660, Kuala Lumpur; ${ }^{2}$ Biodiversity Unit, Institute of Bioscience, Universiti Putra Malaysia, 43400, \\ Serdang, Selangor; E-mails: shamsulkhamis73@gmail.com, shamsul@ibs.upm.edu.my
}

\begin{abstract}
A 2-ha permanent plot was established in two different forest types. These forest were chosen to present the two different geographical and the Orang Asli tribes. The first plot study was conducted at Batu Papan Forest Reserve, Gua Musang, Kelantan were the area is lowland forest and the Orang Asli Bateq is permenantly comunity. The second one was established in upper hill forest at Sungai Kial Forest Reserve, Cameron Highland, Pahang were the Orang Asli Semai is main comunity. All specimens were collected, identified and deposited at IBS Herbarium, UPM. A total 49 species from 24 families was recorded of which most of the species are native. Plant parts most commonly used are roots, leaves, stems, rhizomes or tubers and sap. Many species of plants are used in rituals for healing and protection followed by herbal medicines for restoring and protecting post partum mothers. Some species used for treating various ailments encountered by the villagers ranging from minor ailments and complaints such as itch and flatulence to more serious conditions such as cancer or food poisoning. From this study, the knowledge and usage of medicinal plants is decreasing due to various factors such as modern medicines are easily available, the younger generation are less interested in folk medicine, changes in habitat causing certain medicinal plants to be unavailable or less available.
\end{abstract}

